\title{
When the Self Becomes Other
}

\section{Toward an Integrative Understanding of the Processes Distinguishing Adaptive Self-reflection from Rumination}

\author{
Ethan Kross \\ University of Michigan, Ann Arbor, Michigan 48109-1109, USA
}

\begin{abstract}
How can people adaptively analyze and "work through" negative feelings without ruminating? This paper will briefly review findings from an integrative program of research, which suggests that a critical factor determining whether people's attempts to adaptively reason about negative experiences succeed or fail is the type of self-perspective they adopt. That is, whether people analyze their feelings from a self-immersed or self-distanced perspective. The implications of shifting self-perspectives for subjective experience, autonomic nervous system reactivity, and neural activity are discussed.
\end{abstract}

Key words: rumination; emotion regulation; self-reflection; psychological distance; fMRI; self-regulation; coping; mindfulness

Viktor Frankl, one of the great psychiatrists of the $20^{\text {th }}$ century, devoted much of his life to understanding how people can adaptively cope with distressing life events. After enduring life in a Holocaust concentration camp, Frankl ${ }^{1}$ described the conditions that allowed him and his fellow prisoners to survive as follows:

\section{....Nietzche's words, 'He who has a why to live for can bear with almost any how', could be the guiding motto for all psychotherapeutic and psy- chohygienic efforts... whenever there was an op- portunity for it, one had to give [Holocaust Con- centration Camp Prisoners] a why - an aim - for their lives, in order to strengthen them to bear the terrible how of their existence. (Frankl 1959, p. 84)}

Six decades have passed since Frankl first penned these words. During this time a great deal of evidence has accumulated to support his thesis - self-regulatory strategies and clinical interventions that lead people to reconstrue

Address for correspondence: Ethan Kross, Department of Psychology, 530 Church Street, University of Michigan, Ann Arbor, MI 48109-1109. Voice: 734-763-5640.ekross@umich.edu

This paper was based on a lecture delivered at the Barcelona Social Brain conference. negative events in ways that promote meaning making-that provide people with "why's" to explain their "how's-have been shown to facilitate adaptive coping across a variety of circumstances. ${ }^{2-5}$ What has also become clear during this time, however, is that people experience enormous difficulty doing this precisely when it matters most - when negative feelings are intense and people are motivated to understand their feelings in order to improve them. Rather than facilitating adaptive self-reflection, focusing attention on one's feelings under such circumstances often gives rise to rumination, which serves to maintain and exacerbate distress. $^{6-9}$

Putting these findings together, a challenge emerges: to understand why people's attempts to understand negative feelings at times succeed and at other times fail. This paper will address this issue by reviewing findings from an integrative set of studies, which suggest that a critical factor distinguishing adaptive self-reflection from dysfunctional rumination is the type of selfperspective people adopt while analyzing negative feelings. 


\section{Processes Distinguishing Adaptive and Maladaptive Self-reflection: The Role of Self-perspective}

Prior research indicates that when people recall negative emotional events, they typically do so from a self-immersed perspective. ${ }^{10}$ From this perspective, self-relevant events and emotions are experienced in the first person, through one's own eyes. However, experiences can also be focused on from a self-distanced perspective in which the individual becomes an observer of the self (for example, see Refs. 11-16). In prior research, Kross, Ayduk, and Mischel $^{17}$ proposed that whether people adopt a self-immersed versus self-distanced perspective would critically influence their ability to analyze negative experiences adaptively. They predicted that when individuals focus on negative feelings from a self-immersed perspective, episodic information concerning the specific chain of events (i.e., what happened) and emotions experienced (i.e., what did I feel?) would become accessible, serving to increase negative affect. In contrast, they predicted that analyzing negative feelings from a self-distanced perspective would lead people to focus less on the episodic features of their recalled experience and more on reconstruing it in ways that promote insight and closure. In turn, they predicted that this shift in the content of people's thoughts about their past experience-less recounting and more reconstruing-would lead to reductions in negative affect.

\section{Emotional Reactivity and Construals}

To test these predictions, Kross and colleagues ${ }^{17}$ recruited participants for a study on memory and language. Participants were first instructed to recall a specific time from their past in which they felt overwhelming feelings of anger and hostility. They were then randomly assigned to analyze their feelings from either a self-immersed or self-distanced perspective. Subse- quently, participants rated the extent to which they relived their negative feelings during the experiment and described in writing the stream of thoughts they experienced as they analyzed their feelings. The latter thought content essays were coded for the extent to which they contained recounting statements (i.e., statements in which participants indicated thinking about the specific chain of events and emotions experienced) and reconstruing statements (i.e., statements demonstrating insight and closure).

The results indicated that participants in the self-distanced group displayed significantly lower levels of emotional reactivity compared to participants in the self-immersed group. In addition, analyses of participants' thought content essays indicated that participants who analyzed their feelings from a self-distanced perspective focused relatively less on what happened to them (i.e., recounting) and relatively more on reconstruing the event (e.g., I understand why the fight happened; it might have been irrational but I understand his motivation now). Consistent with the experimenters' predictions, this shift in the content of people's thoughts about their past experience-less recounting and more reconstruing - mediated the effect of the self-perspective manipulations on emotional reactivity. 18

\section{Incremental Utility: Comparisons to Distraction}

The findings reviewed above suggest that directing individuals to analyze negative feelings from a self-distanced perspective helps attenuate emotional reactivity in the short term. But to what extent are these reductions in negative affect substantively significant? One way to address this question is to compare the effects of self-distancing against distraction, a technique that has been shown to be extremely effective at reducing negative affect relative to rumination manipulations in prior work. ${ }^{7}$ Drawing from research indicating that distraction and cognitive reconstrual strategies are equally effective at 
facilitating self-control, ${ }^{19-20}$ Kross and Ayduk $^{21}$ hypothesized that self-distancing and distraction would lead to statistically equivalent reductions in negative affect. Findings from a study that compared the effects of self-distancing, self-immersion, and distraction on short-term emotional reactivity were consistent with this prediction. Whereas both distraction and selfdistancing led to significantly lower levels of emotional reactivity relative to self-immersion, distraction and self-distancing led to the same relatively low levels of emotional reactivity. ${ }^{21}$

\section{From Mind to Body: Implications for Cardiovascular Reactivity}

Another question raised by our initial findings was whether these different ways of analyzing negative experiences impact people on the physiological level. Prior research indicates that rumination delays the amount of time it takes people to physiological recovery from negative events because it leads people to continually rehash the emotionally evocative details of past experiences. $^{22-24}$ To the extent that analyzing negative experiences from a self-distanced perspective attenuates rumination, we predicted that it would influence autonomic nervous system reactivity as well, enhancing the pace of physiological recovery.

Ayduk and $\mathrm{Kross}^{25}$ tested this prediction by randomly assigning participants to analyze an anger experience from either a self-immersed or self-distanced perspective while continuously recording their blood pressure levels. Consistent with predictions, they found that participants in the self-distanced group displayed significantly lower levels of blood pressure reactivity (relative to baseline) compared to the selfimmersed group both during the experiment, when participants were explicitly instructed to analyze their feelings, and $20 \mathrm{~min}$ after the experiment was over (during a recovery period). Given the negative physical health implications associated with delayed physiological recovery, ${ }^{26,27}$ these findings suggest that self- distancing may have important physical health implications.

\section{Long-Term Buffering Effects}

The findings reviewed thus far demonstrate that self-distancing is effective at reducing emotional and physiological reactivity in the short term. But what about protective buffering effects? Does analyzing feelings from a selfdistanced perspective enable people to adaptively "work through" and process disturbing experiences in ways that reduce their future negative impact?

To address these questions Kross and Ayduk $^{21}$ recruited participants for two short-term longitudinal studies. During Session 1 of each study, participants recalled a depression-related experience and were then randomly assigned to a self-immersion, self-distancing, or distraction condition. Participants then returned to the laboratory either $24 \mathrm{~h}$ (study 1) or 7 days (study 2) later for additional testing. During this second session all participants recalled and analyzed the same experience they thought about during Session 1, without receiving any additional instructions regarding how they should think about the event. They then indicated how upset they felt and how much time they spent thinking about their past experience between the two sessions.

Regardless of whether the time lag between the two sessions was 1 day or 7 days, the results were the same-whereas both self-distancing and distraction led to lower levels of negative affect compared to the self-immersion strategy during Session 1, during Session 2 self-distancing led to the lowest levels of negative affect ${ }^{21}$ (also see Ref. 28). Participants in the self-distancing group also displayed the lowest levels of recurring thoughts about their recalled negative experiences during the time period separating the two sessions. Taken together, these findings suggest that analyzing negative experiences from a self-distanced perspective have both adaptive short-term and long-term implications. 


\section{From the Laboratory to Everyday Life: Spontaneous Self-distancing}

To the extent that adopting a self-distanced perspective aids people in their ability to cope adaptively with trying emotional circumstances, one might expect some people to spontaneously implement this technique. Consider, for example, a recent description of President Barak Obama by New York Times columnist David Brooks (2008):

\begin{abstract}
When Bob Schieffer asked him tough questions during the debate Wednesday night, he would step back and describe the broader situation. When John McCain would hit him with some critique - even about fetuses being left to die on a table - he would smile in amusement at the political game they were playing. At every challenging moment, his instinct was to self-remove and establish an observer's perspective.
\end{abstract}

This passage suggests that Obama, a public figure known at this point in time for his capacity for self-control, adopts a self-distanced (i.e., observer) perspective to regulate his feelingsat least in some situations. The question for us is whether this is true of other people as well? That is, do some people spontaneously selfdistance when analyzing negative feelings, and does doing so lead to the same types of emotion regulatory consequences as when people are instructed to do this in the laboratory?

Ayduk and $\mathrm{Kross}^{29}$ examined these issues by cueing participants to recall and analyze a recent negative interpersonal experience without making any reference to what type of selfperspective they should adopt as they focused on their feelings. Subsequently, participants were asked to indicate the extent to which they adopted a self-immersed versus self-distanced perspective as they focused on their feelings using a seven-point Likert scale.

The results indicated that the more participants spontaneously self-distanced, the less emotional and physiological reactivity they displayed. In another study spontaneous selfdistancing at time 1 predicted lower levels of emotional reactivity when participants were asked to analyze the same event approximately 6 weeks later and was correlated with lower levels of intrusive thoughts during the 6-week period separating the two sessions. Thus collectively, emerging findings suggest that people do, in fact, spontaneously self-distance and that doing so is linked with a similar pattern of adaptive outcomes as when self-distancing is experimentally manipulated in the laboratory.

\section{From Mind to Brain: Neural Signatures of Adaptive Self-reflection}

Recent work has also begun to examine whether distinct patterns of neural activity underlie these different ways of reflecting on negative past experiences. In one study, for example, Kross, Davidson, Weber, and Ochsner ${ }^{30}$ used functional magnetic resonance imaging (fMRI) to monitor brain activity while participants thought about intense negative autobiographical experiences using strategies designed to facilitate versus undermine adaptive self-reflection. Specifically, on some trials participants were instructed to focus concretely on the specific episodic details surrounding their past experiences (i.e., conceptually similar to self-immersion). On other trials they were directed to focus on their feelings as mental events that were psychologically distanced from the self (i.e., conceptually similar to self-distancing).

The results of this study revealed increased levels of activity in brain regions involved in selfreferential processing (medial prefrontal cortex, Brodmann Area 10) and emotion dysregulation (subgenual anterior cingulate cortex, Brodmann Area 25) when participants implemented the self-immersion strategy in comparison to the self-distancing strategy. In addition, activity in both of these regions correlated positively with the increases in self-report negative affect that participants reported experiencing on self-immersion versus self-distancing trials.

The fact that activity in the subgenual anterior cingulate cortex (BA25) distinguished 
between these two different ways of focusing on negative autobiographical memories in this study was particularly noteworthy. A number of recent studies have implicated elevated levels of activity in this region in depression, ${ }^{31,32}$ a mood disorder characterized by ruminative ideation. ${ }^{6,7}$ For example, activity in this region is elevated among clinically depressed individuals at rest, ${ }^{33}$ declines in response to antidepressant treatment for depression, ${ }^{34-36}$ and predicts treatment response with cognitive behavioral therapy. ${ }^{37}$ In addition, reducing activity in this region via deep brain stimulation techniques has been associated with remissions of depression in previously treatment-refractory patients. ${ }^{38}$ Thus, the fact that the self-distancing technique leads to reductions in activity in this brain region provides an important additional layer of evidence suggesting that this strategy may be useful for buffering people against rumination.

\section{Concluding Comments}

The main goals of this paper were to shed light on why people's attempts to analyze and "work through" negative feelings fail, and to demonstrate how such failures can be overcome-by adopting a self-distanced perspective when analyzing negative events rather than a self-immersed perspective. Whether or not shifting from a self-immersed to a self-distanced perspective facilitates adaptive emotional analysis among different types of clinical populations (e.g., individuals with major depressive disorder or anxiety disorders) or in response to different types of negative affect-eliciting situations (the studies reviewed in this paper focused only on anger and depression-related events) currently remains unknown. Addressing these questions in the future is important for building a more integrative understanding of the processes that underlie adaptive versus maladaptive forms of self-reflection.

\section{Acknowledgments}

The research described in this paper was supported by grants from the National Institute of Mental Health (MH0393499) and National Research Service Award and National Science Foundation fellowships.

\section{Conflicts of Interest}

The author declares no conflicts of interest.

\section{References}

1. Frankl, V.E. 1959. Man's Search for Meaning. Ilse Lasch, Trans. Simon \& Schuster, Inc. New York (Original work published in 1946).

2. Austenfeld, J.L. \& A.L. Stanton. 2004. Coping through emotional approach: A new look at emotion, coping, and health-related outcomes. F. Pers. 72: 1335-1363.

3. Pennebaker, J.W. \& C.K. Chung. 2007. Expressive Writing, Emotional Upheavals, and Health. Oxford University Press. New York.

4. Resick, P.A. \& M.K. Schnicke. 1992. Cognitive processing therapy for sexual assault victims. 7. Consult. Clin. Psychol. 70: 748-756.

5. Wilson, T.D. \& D.T. Gilbert. 2008. Explaining away: A model of affective adaptation. Perspect. Psychol. Sci. 3: $370-386$.

6. Nolen-Hoeksema, S. 1991. Responses to depression and their effects on the duration of depressive episodes. F. Abnorm. Psychol. 100: 569-582.

7. Nolen-Hoeksema, S.B., E. Wisco \& S. Lyubomirsky. 2008. Rethinking rumination. Perspect. Psychol. Sci. 3: 400- 424.

8. Teasdale, J.D. 1988. Cognitive vulnerability to persistent depression. Cogn. Emotion 2: 247-274.

9. Mor, N. \& J. Winquist. 2002. Self-focused attention and negative affect: A meta-analysis. Psychol. Bull. 128: 638-662.

10. Nigro, G. \& U. Neisser. 1983. Point of view in personal memories. Cogn. Psychol. 15: 467-482.

11. James, W. 1890. The Principles of Psychology. Holt. New York.

12. Libby, L. \& R. Eibach. 2002. Looking back in time: Self-concept change affects visual perspective in autobiographical memory. 7. Pers. Soc. Psychol. 82: 167-179.

13. McIsaac, H.K. \& E. Eich. 2002. Vantage point in episodic memory. Psychon. B Rev. 9: 146150. 
14. Pronin, E. \& L. Ross. 2006. Temporal differences in trait self-ascription: When the self is seen as an other. 7. Pers. Soc. Psychol. 90: 197-209.

15. Robinson, J.A. \& K.K. Swanson. 1993. Field and observer modes of remembering. Memory 1: 169-184.

16. Vasquez, N.A. \& R. Buehler. 2007. Seeing future success: Does imagery perspective influence achievement motivation. Pers. Soc. Psychol. Bull. 33: 13921405.

17. Kross, E., O. Ayduk \& W. Mischel. 2005. When asking 'why' does not hurt: Distinguishing rumination from reflective processing of negative emotions. Psychol. Sci. 16: 709-715.

18. Strack, F., N. Schwarz \& E. Gschneidinger. 1985. Happiness and reminiscing: The role of time perspective, affect, and mode of thinking. 7. Pers. Soc. Psychol. 49: 1460-1469.

19. Mischel, W. \& M.L. Rodriguez. 1993. Psychological distance in self-imposed delay of gratification. In The Development and Meaning of Psychological Distance. R.R. Cocking \& K.A. Renninger, Eds.: Lawrence Earlbaum Associates. Hillsdale, NJ.

20. Mischel, W., Y. Shoda \& M.L. Rodriguez. 1989. Delay of gratification in children. Science 244: 933-938.

21. Kross, E. \& O. Ayduk. 2008. Facilitating adaptive emotional analysis: Distinguishing distanced-analysis of depressive experiences from immersed-analysis and distraction. Pers. Soc. Psychol. Bull. 34: 924-938.

22. Gerin, W., K.W. Davidson, N.J.S. Christenfeld, et al. 2006. The role of angry rumination and distraction in blood pressure recovery from emotional arousal. Psychosom. Med. 68: 64-72.

23. Glynn, L.M., N. Christenfeld \& W. Gerin. 2002. The role of rumination in recovery from reactivity: Cardiovascular consequences of emotional states. Psychosom. Med. 64: 714-726.

24. Surchday, S., M.M. Carter, C. Ewart, et al. 2004. Anger cognitions and cardiovascular recovery following provocation. 7. Behav. Med. 27: 319-341.

25. Ayduk, O. \& E. Kross. 2008. Enhancing the pace of recovery: Self-distanced analysis of negative experiences reduces blood pressure reactivity. Psychol. Sci. 19: 229-231.

26. Brosschot, J.F., W. Gerin \& J.F. Thayer. 2006. The perseverative cognition hypothesis: A review of worry, prolonged stress-related physiological activation, and health. F. Psychosom. Res. 60: 113-124.

27. McEwen, B.S. 1998. Protective and damaging effects of stress mediators. New England F. Med. 338: 171179.

28. Ayduk, O. \& E. Kross. 2008. Asking 'why' from a distance facilitates emotional processing: A reanalysis of Wimalaweera and Moulds (2009). Behav. Res. Ther. 47: 88-92.

29. Ayduk, O. \& E. Kross. 2009. Reflecting on the Self. . .From a Distance: Implications of Spontaneous Self-distancing for Emotional Processing. University of California, Berkeley manuscript.

30. Kross, E., M. Davidson \& J. Weber, et al. 2008. Coping with emotions past: The neural bases of regulating affect associated with negative autobiographical memories. Biol. Psychiatry. 65: 361-366.

31. Drevets, W.C. \& J. Savitz. 2008. The subgenual anterior cingulated cortex in mood disorders. CNS Spectrum 13: 663-681.

32. Ressler, K. \& H.S. Mayberg. 2007. Targeting abnormal neural circuits in mood and anxiety disorders: From the laboratory to the clinic. Nat. Neurosci. 10: 1116-1124.

33. Greicius, M.D., B.H. Flores, V. Menon, et al. 2007. Resting-state functional connectivity in major depression: Abnormally increased contributions from subgenual cingulate cortex and thalamus. Biol. Psychiatry 62: 429-437.

34. Fu, C.H., S.C. Williams, A.J. Cleare, et al. 2004. Attenuation of the neural response to sad faces in major depression by antidepressant treatment: a prospective, event-related functional magnetic resonance imaging study. Arch. Gen. Psychiat. 6: 877889.

35. Goldapple, K., Z. Segal, C. Garson, et al. 2004. Modulation of cortical-limbic pathways in major depression: treatment-specific effects of cognitive behavior therapy. Arch. Gen. Psychiat. 61: 34-41.

36. Sheline, Y.I., D.M. Barch, J.M. Donnelly, et al. 2001. Increased amygdala response to masked emotional faces in depressed subjects resolves with antidepressant treatment: an fMRI study. Biol. Psychiatry 50: 651-658.

37. Siegle, G.J., C.S. Carter \& M.E. Thase. 2006. Use of fMRI to predict recovery from unipolar depression with cognitive behavior therapy. Am. F. Psychiatry 163: 735-738.

38. Mayberg, H.S., A.M. Lozano, V. Voon, et al. 2005. Deep brain stimulation for treatment-resistant depression. Neuron 45: 651-660. 